\title{
CONCEITOS AXIOLÓGICOS BAKHTINIANOS EM PROPAGANDA IMPRESSA
}

\author{
Renilson José MENEGASSI* \\ Rosilene da Silva de M. CAVALCANTI*
}

- RESUMO: Este artigo aborda os aspectos axiológicos presentes nos conceitos de extraverbal, julgamento de valor e entoação, discutidos pelo Círculo de Bakhtin, apresentados especificamente, por escolha, em Volochinov e Bakhtin (1926), Bakhtin e Volochinov (2006) e Bakhtin (2003). Também relaciona esses conceitos com os estudos realizados por pesquisadores como Geraldi (1997), Clark e Holquist (1998), Souza (2002), Tezza (2003), Morson e Emerson (2008), Faraco (2009) e Sobral (2009), buscando refletir como são apresentados em enunciados concretos utilizados em situações comunicativas sociais. Além disso, o texto exemplifica esses conceitos ao realizar a leitura de uma propaganda produzida para a mídia impressa, demonstrando os possíveis e diferentes sentidos obtidos na leitura.

- PALAVRAS-CHAVE: Extraverbal. Juízo de valor. Entoação. Enunciado.

\section{Considerações iniciais}

Este texto apresenta uma reflexão teórico-analítica sobre alguns aspectos axiológicos presentes nos conceitos de extraverbal, julgamento de valor e entoação, discutidos pelo Círculo de Bakhtin, a respeito do caráter dialógico da linguagem. Para isso, fundamenta-se em pressupostos teóricos da concepção dialógica de linguagem, com ênfase na abordagem sócio-histórica, a partir de Bakhtin ${ }^{1}$ e dos pesquisadores que desenvolvem pesquisas neste escopo teórico.

Assim, o texto tem como objetivo levantar os conceitos de extraverbal, julgamento de valor e entoação, sabendo-se dos riscos que tal escolha pode ter, especificamente em algumas obras bakhtinianas ${ }^{2}$, como: Volochinov e Bakhtin

* UEM - Universidade Estadual de Maringá. Centro de Ciências Humanas, Letras e Artes - Departamento de Letras. Maringá - PR - Brasil. 87020-900 - renilson@wnet.com.br

** UEM - Universidade Estadual de Maringá - Centro de Ciências Humanas, Letras e Artes - Departamento de Letras. Maringá - PR - Brasil. 87033-330 - rmcavalcant@ig.com.br

1 Ao nos referirmos a Bakhtin, estamos também tratando das expressões "Círculo de Bakhtin" e "bakhtiniano" como tendo o mesmo valor semântico.

2 Não é intuito deste texto apresentar um rastreamento dos conceitos discutidos nas obras do Círculo de Bakhtin, por isso da escolha pelas obras mais acessíveis ao público brasileiro, que têm ampla circulação no país. 
(1926) - Discurso na vida e discurso na arte, Bakhtin e Volochinov (2006) - Marxismo e Filosofia da Linguagem e Bakhtin (2003) - Estética da criação verbal. Também tem como objetivo relacionar esses conceitos a estudos realizados por pesquisadores como Geraldi (1997), Clark e Holquist (1998), Souza (2002), Tezza (2003), Morson e Emerson (2008), Faraco (2009) e Sobral (2009), que já os discutiram amplamente. Numa segunda parte do texto, propõe-se um gesto de leitura analítico em um gênero discursivo de circulação na mídia impressa brasileira, uma propaganda, procurando observar como esses conceitos permitem derivadas compreensões do texto escolhido, colaborando com os estudos sobre a complexa realidade da linguagem humana.

\section{Extraverbal, julgamento de valor e entoação na constituição do enunciado}

Para o Círculo de Bakhtin, a interação é a própria concepção de linguagem e constitui a realidade fundamental da língua. Por sua vez, Bakhtin e Volochinov (2006, p.123) afirmam que "[...] toda palavra comporta duas faces. Ela é determinada tanto pelo fato de que procede de alguém, como pelo fato de que se dirige para alguém.", o que lhe garante o caráter dialógico, mesmo que este diálogo seja do indivíduo com o próprio indivíduo, uma de suas muitas manifestações. Nestas, o produto da interação entre indivíduos socialmente organizados é a enunciação, que tem como centro organizador o meio social e não poderá ser compreendida e explicada fora desse vínculo com a situação concreta de sua manifestação. Ela "[...] só se realiza no curso da comunicação verbal, pois o todo é determinado pelos seus limites, que se configuram pelos pontos de contato de uma determinada enunciação com o meio extraverbal e verbal (isto é as outras enunciações)." (BAKHTIN; VOLOCHINOV, 2006, p.127). Assim, o enunciado é a unidade dessa comunicação discursiva, um elo no processo comunicativo, sendo irrepetível, pois seu contexto e sua razão de ser diferem dos de qualquer outro enunciado, mesmo sendo verbalmente idênticos. Esse caráter unívoco e irrepetível se dá justamente por sua característica axiológica, valorativa, que o sempre acompanha, manifestando-se polissemicamente em função da situação comunicativa em que o enunciado ocorre. Dessa forma, cada enunciação é única, mesmo que o enunciado verbal seja repetido, ele não será valorativamente o mesmo, pois o contexto de produção é sócio-histórico-contextual-discursivamente diverso, considerando-se aqui tanto a sua produção inicial, quanto seus modos de recepção, nas diversas possibilidades complexas da concretização da linguagem. Sobre isso, Morson e Emerson, estudiosos das ideias do Círculo, comentam:

Dois enunciados verbalmente idênticos nunca significam a mesma coisa [...]. O contexto nunca é o mesmo. O falante e o ouvinte, o escritor e o leitor, também mudam: não importa quantas características possam 
compartilhar, dois enunciados nunca compartilham tudo. Cada um deles é único e cada qual, portanto, significa e é entendido como significando algo diferente, mesmo quando são verbalmente os mesmos. (MORSON; EMERSON, 2008, p.142).

Deste modo, se o enunciado for retirado do contexto, que nem sempre é fisicamente o mesmo, perde a chave tanto de sua forma quanto de seu conteúdo, restando apenas a abstração linguística e semântica que não permanecerão por muito tempo, por lhes faltar a base para sua síntese orgânica, isto é, o seu valor na enunciação. Esta, por sua vez, definida, constitui as possibilidades de compreensão desse enunciado.

Reflete-se, portanto, no enunciado, a interação social do falante, do ouvinte e do tema tratado como o produto e a fixação, no material verbal, de um ato de comunicação vivo entre os interactantes. Ele é pleno de tonalidades dialógicas, e sem levá-las em conta é impossível entender até o fim o estilo de um enunciado (BAKHITIN, 2003). Assim, o enunciado concreto une os participantes da situação comum como co-participantes que conhecem, entendem e avaliam a situação de maneira próxima. É o conhecimento da situação comum que vai garantir aos interlocutores a interação discursiva em seus contextos verbais e extraverbais. Essa situação, por sua vez, tem um mínimo de acabamento entre os interactantes, para que possa haver a compreensão no jogo da linguagem, caso contrário, não se estabelece e, consequentemente, não há um processo enunciativo condizente.

Da mesma maneira, para Volochinov e Bakhtin (1926), o enunciado é um todo significativo que compreende duas partes: a parte percebida ou realizada em palavras e a parte presumida. A primeira se constitui por meio dos fatores verbais, marcas linguísticas e até mesmo visuais, que denominamos de verbovisual, enquanto a segunda é constituída pelo extraverbal nas interações sociais, históricas e discursivas em que os indivíduos convivem, isto é, por conhecimentos que não estão explicitamente demarcados na materialidade analisada, mas, sim, nos implícitos sócio-histórico-ideológico-contextual da produção, nas duas manifestações já apontadas. Nesse bojo, o extraverbal é caracterizado pelo que não foi dito explicitamente, portanto, não marcado em linguagem verbo-visual, em que o contexto pode ser compreendido pelos envolvidos na interação por meio de circunstâncias não linguísticas conhecidas pelos interlocutores e que complementam o sentido que se quer dar aos enunciados. Muitas vezes, pode ser visto apenas como uma imagem que complementa os enunciados, o não verbal, mas vai além ao manter a característica social que faz parte das interações verbais. Cabe justamente ao interlocutor identificar essas características no meio social, para que a compreensão do enunciado se qualifique, permitindo que a interação se instale e a enunciação se efetive, gerando o ato comunicativo. 
Segundo os pressupostos do Círculo, o extraverbal é constituído por três elementos: 1) o horizonte espacial ideacional que envolve o conhecimento físico, espacial em que o enunciado está se realizando, que é visível aos interlocutores, e o conhecimento ideológico dos falantes sobre as condutas que devem ter nesse espaço determinado; 2) o conhecimento e a compreensão comum da situação comunicativa por parte dos interlocutores, que envolve o contexto históricocultural e os conhecimentos que os envolvidos têm em comum sobre os aspectos que estão ali envolvidos, como o tema discutido, as posições sociais de cada interlocutor etc.; 3) a avaliação comum da situação, os valores que sustentam essa interação e que compõem o horizonte social, realizada pelos participantes para que a enunciação se estabeleça, se constitua e, principalmente, seja compreendida. Esse três elementos, além de compor o extraverbal, no enunciado se complementam e na situação pragmática não é possível separá-los, pois para entendê-los é preciso partir do texto. Para defini-los, aqui, tentou-se, para uma melhor compreensão e organização metodológica, conceituá-los separadamente, por uma questão apenas didática, sabendo que sua realização é feita num conjunto concomitante e recursivo.

Nesse sentido, o discurso verbal nasce de uma situação pragmática extraverbal, ou seja, o enunciado, mais seu entorno físico, espacial, ideológico e cultural, está diretamente ligado à vida em si e se for desvinculado dela perderá a sua significação. Sobre a questão, Clark e Holquist (1998, p.244) comentam: "O traço diferenciador do discurso cotidiano não é o seu vocabulário ou o seu padrão sintático, porém a sua relativa dependência do contexto imediato.", isto em qualquer situação, mesmo na escrita. Essa dependência do contexto exige, por parte dos participantes do ato comunicativo, que conheçam, ambos, pelo menos alguns traços em comum sobre o que se diz, a situação em que se produz e as condições de recepção constituídas, para que a compreensão se estabeleça. Uma pessoa que desconhece o contexto extraverbal imediato não compreenderá completamente o enunciado tal como o interlocutor o desejaria. Basta o desconhecimento, pelos envolvidos na interação, de um dos elementos que compõem o extraverbal para que sua compreensão seja falha, pois os enunciados surgem e terminam no processo da interação social entre os participantes da enunciação.

O extraverbal está integrado ao enunciado, favorecendo a interação comunicativa entre os interlocutores. Para o Círculo, também é denominado parte presumida ou contexto imediato a parte conhecida dos envolvidos na enunciação e pode ter um escopo maior ou menor, podendo o horizonte comum expandir-se no tempo e no espaço. Se o horizonte real presumido de um enunciado é estreito, a mudança mais momentânea dentro deste horizonte pode se tornar a parte presumida. Se o campo de alcance for mais amplo, o enunciado pode agir apenas 
se sustentado em fatores constantes e estáveis da vida e em avaliações sociais substantivas e fundamentais. Isto significa que, quanto mais amplas e substanciais forem a interações sociais, maior conhecimento de situações extraverbais os interlocutores passam a ter.

Uma comunidade ou grupo social possui valores específicos que são reconhecidos socialmente. Por exemplo, dos membros do grupo social dos religiosos, espera-se que sejam benevolentes, que se preocupem com o próximo, sejam amorosos, que não sejam dados a atos contrários aos valores religiosos, como o alcoolismo, a prostituição etc., como exemplos típicos de qualquer ramo religioso. Esses valores estão arraigados na sociedade e formam os valores presumidos, o que faz com que os enunciados funcionem e sejam entoados e avaliados diferentemente em cada situação discursiva, porém sempre os tendo como presumidos, como certos. Por isso, a possibilidade de um membro desse grupo aparecer embriagado desencadeará enunciados de censura e contrariedade, também presumidos de exclusão e penalização, enfim, valorativos em função do grupo social.

Ainda sobre essa conceituação, Geraldi $(1984,1997)$ foi um dos pioneiros na interpretação das ideias do Círculo de Bakhtin no país, voltadas às perspectivas do ensino. Ele declara que o indivíduo expressa seu ponto de vista sobre o mundo por meio do discurso, apregoado com seus valores presumidos, aprendendo e desenvolvendo a língua materna com textos em situações valorativas concretas. Por isso, o autor considera a produção de textos (orais e escritos) como ponto de partida (e ponto de chegada) de todo o processo de ensino/aprendizagem, afirmando que os enunciados constituem a materialidade dos discursos e sobre eles se inicia e se finda a enunciação.

Ao apresentar suas reflexões sobre o ensino, Geraldi fundamenta seu trabalho na concepção dialógica da linguagem, que contribui para a construção de novas alternativas ao ensino de língua, sem que seja preciso abandonar conhecimentos historicamente produzidos. A interação, nessa perspectiva, não se dá fora de um contexto social e histórico mais amplo, sofrendo, assim, as interferências, os controles e as seleções impostas pela formação social. Nesse sentido, o conceito de extraverbal é encontrado nos estudos do autor como sendo denominado por "contexto" ou "situação histórico-social", ou seja, "[...] o espaço no qual se dão as interações entre os sujeitos." (GERALDI, 1997, p.13).

Sobral (2009, p.90), por sua vez, valoriza o conceito de extraverbal ao considerar sua importância na compreensão do enunciado. Para o autor, o enunciado só pode ser entendido "[...] considerando o processo de sua produção, de sua circulação no mundo e de sua recepção por outros sujeitos.", o que reafirma o já posto. 
Faraco contribui com essa proposta ao afirmar que "[...] todo enunciado emerge sempre e necessariamente num contexto cultural saturado de significados e valores e é sempre um ato responsivo, isto é uma tomada de posição." (FARACO, 2009, p.25). Isso pode ser exemplificado na frase: "Ele é gay!". Enquanto frase, é neutra, mas, como enunciado, pode expressar vários sentimentos, dependendo do tom utilizado no seu proferimento, de como o autor se constitui em relação ao outro. Os valores possíveis de atribuição, como desprezo, espanto, admiração, afirmação etc., dependem da situação em que a frase se encontra e como ela se constitui como enunciado. Dessa forma, a situação extraverbal constitui, então, valores diferenciados, principalmente numa sociedade que busca a convivência com esses valores e com a diversidade social como um de seus objetivos de evolução.

Assim, os julgamentos de valor presumidos são atos sociais regulares e essenciais (VOLOCHINOV; BAKHTIN, 1926) e se configuram por meio do posicionamento ideológico dos interlocutores envolvidos no discurso. Se o julgamento de valor for condicionado pela existência de uma dada comunidade, considerando-se suas relações ideológicas, ele se torna uma matéria de crença dogmática, alguma coisa tida como certa por todos os participantes do grupo social. Entretanto, se for verbalizado e justificado, torna-se duvidoso, pois, ao separar-se do seu referente, perde a conexão com as condições existenciais do seu grupo dado, ou seja, um "[...] julgamento de valor qualquer existe em sua totalidade." (VOLOCHINOV; BAKHTIN, 1926, p.7).

Nessa perspectiva valorativa existente no enunciado, Geraldi, pensando nas questões que envolvem o ensino, propõe um quadro hipotético com questionamentos que direcionam as respostas que um aluno pode construir ao ser solicitado para escrever um texto, "[...] uma sequência verbal escrita formando um todo acabado, definido e publicado." (GERALDI, 1997, p.101), que já orienta a compreensão do julgamento de valor de sua própria produção escrita:

1. Quem sou eu para lhe falar assim?

2. Quem é ele para eu lhe falar assim?

3. Quem sou eu (professor) para que ele me fale assim?

4. Quem é ele (aluno) para que ele me fale assim?

5. De que lhe falo eu?

6. De que ele me fala?

7. O que ele pretende de mim falando desta forma?

8. O que o aluno pretende de si próprio falando dessa forma? (GERALDI, 1997, p.69-71). 
Nestes questionamentos estão marcados os possíveis julgamentos de valor que são construídos socialmente, carregados da ideologia constitutiva do grupo ao qual o locutor pertence, no caso, a escola e seus interactantes. Por exemplo, ao questionar "Quem é ele para eu lhe falar assim?", o aluno levanta do arcabouço ideológico que construiu ao longo de sua vida, por meio das situações vividas, valores que auxiliam no seu posicionamento como sujeito ativo: ele é o professor, a pessoa que tem que saber; é ele quem corrige e diz o que é certo ou errado sobre meu texto; é ele quem vai corrigir, portanto devo escrever o que ele quer que eu escreva, pois este é o valor estabelecido nas nossas relações. São esses julgamentos de valor ideologicamente constituídos que definem o discurso na interação. Percebe-se, nos estudos de Geraldi, que os conceitos de julgamento de valor e entonação são apresentados imbricados, dificultando sua conceituação separada.

Nos estudos de Sobral, em período posterior a Geraldi, os conceitos de julgamento de valor e entoação aparecem unidos, chamado de "entoação avaliativa", o que, pela nomenclatura, já define o tom como marca de avaliação do locutor, um posicionamento ativo. Assim, "[...] toda enunciação envolve um tom avaliativo impresso pelo sujeito e suas alterações verbais, de acordo com suas relações com seu interlocutor e o momento da interlocução." (SOBRAL, 2009, p.83-84). Como se nota, o tom avaliativo definido pelo sujeito leva em conta o interlocutor e o momento de realização do ato comunicativo, com seus enunciados efetivos. Dependendo a quem se dirige, o locutor define seu tom avaliativo. Por exemplo: um pai, utilizando-se de sua autoridade, diz ao filho: "-Vá para dentro!". O filho, ao reconhecer a autoridade paterna, vai obedecer ou não, dependendo da sua relação com o pai. Já, se este mesmo pai dirigir-se a um menino qualquer e der a mesma ordem, não conseguirá o pretenso resultado, pois mudou o interlocutor e o momento da interlocução, consequentemente, altera-se, também, a relação valorativa pressuposta. Isso se explica pelo fato de que um sujeito diz algo a outro a partir de uma dada posição social, que resulta da relação do sujeito com o outro na interação (SOBRAL, 2009), ou seja, nossa mera entoação carrega obrigatoriamente nossa palavra de atitude valorativa (TEZZA, 2003).

Ainda, em Sobral (2009), a entoação avaliativa se constitui em relação à resposta ativa presumida do interlocutor, justamente por saberem os valores comuns a ambos. Assim, o discurso vai se constituindo de forma interativa, respeitando as alternâncias entre os interlocutores. Nessa perspectiva, retoma-se Clark e Holquist (1998), ao afirmarem que o lugar a partir do qual algo é percebido determina o significado daquilo que é observado, marcando o valor dos envolvidos na construção do enunciado. Essa percepção envolve os pressupostos discutidos por Geraldi, a partir da noção de valor do Círculo de Bakhtin, agregando-se aos de Sobral (2009). 
A entoação, dessa forma, estabelece um elo firme entre o discurso verbal e o contexto extraverbal. É responsável por transportar o discurso para além das fronteiras do verbal, por estar na fronteira do verbal com o não verbal, do dito com o não dito, sendo compreensível juntamente com o julgamento de valor estabelecido pelo enunciado e o próprio ato comunicativo.

Ao se pensar sobre esse conceito, nos modos formais da gramática, o Dicionário Aurélio estabelece que entoação significa "[...] modulação na voz de quem fala ou recita, inflexão, entoação." (FERREIRA, 2008, p.353). Complementando essa definição, retomamos Câmara Junior (2007, p.130) ao defini-la como "[...] escala de elevação e abaixamento da voz com que se enuncia uma frase.", que também explica que a entoação é a responsável por determinar a interrupção de uma frase ou sua classificação. Já para Bakhtin e seu Círculo, o conceito de entoação é mais abrangente do que esse puramente gramatical. É social, envolvendo também os aspectos fonológicos, mais a modulação dada à voz, fazendo com que uma mesma frase se constitua em diferentes enunciados, por isso "[...] uma entoação criativamente produtiva, segura e rica." (VOLOCHINOV; BAKHTIN, 1926, p.8) está diretamente ligada à posição ocupada pelo locutor num determinado momento, por isso sujeita a mudanças.

Devido à capacidade de modificar um único enunciado, dando várias significações, a entoação é considerada criativamente produtiva nos seus aspectos sociais e discursivos. Para exemplificar esse conceito, Volochinov e Bakhtin (1926) utilizam como ilustração duas pessoas que, sentadas numa sala de jantar, veem começar a nevar e um deles diz! "- Bem!". Um enunciado que isoladamente é vazio e sem sentido torna-se completo e pleno de significação quando inserido no contexto extraverbal. É pelo que viam conjuntamente - os flocos de neve pela janela -, pelo conhecimento comum - a época do ano: inverno - e a avaliação comum sobre a situação - a marca de que o inverno chegou são os flocos de neve que caem, juntamente com o frio típico da estação - que o enunciado "- Bem!" tem valor específico nessa situação, definindo, inclusive, compreensões diversas, mas únicas para os interlocutores no contexto específico descrito: a) o inverno chegou; b) já era tempo de o inverno chegar; c) a neve começou a cair, o frio chegou junto; d) é hora de ir embora, pois começou a nevar etc.

A entoação está relacionada ao outro, ao conceito de alteridade, obrigatoriamente, pois é justamente o outro quem vai avaliar e valorar o enunciado a partir da entoação. Sua escolha depende do significado que o locutor quer dar ao enunciado, fazendo com que uma mesma palavra atenda a diferentes enunciações. Nesse caso, a entoação é a marca pessoal do locutor, sua presença e seus valores no enunciado. Isso pode ser observado por meio do enunciado: "-Mãe!". Tomado isoladamente, é um enunciado vazio, mas se pronunciado com entoação expressiva pode ter diferentes significações, causando valores diversos 
aos interlocutores. O que vai determinar o sentido é o contexto extraverbal no qual estiver inserido. Por exemplo, uma filha ao deparar-se com sua mãe, fazendo algo que não acreditava que ela fosse capaz de fazer, admirada, coloca as mãos na cintura e diz: "- Mãe!". Este enunciado vem carregado de admiração diante do inesperado. Entretanto, este mesmo enunciado poderá acontecer em outro contexto. Uma criança adoentada, dengosamente chama sua mãe: "- Mãe!". A partir destes exemplos, nota-se que a entoação é a responsável em marcar a presença do interlocutor no discurso, mesmo na escrita, uma vez que as descrições do contexto em que o enunciado aparece são descritas para que o leitor possa compreender e fazer as relações necessárias para seu entendimento, basta ao leitor responder às provocações propostas pelo autor, através de suas atitudes responsivas diversas.

Assim, a entoação na fala concreta é muito mais metafórica do que as palavras usadas, estando fortemente ligada à metáfora articulatória e gesticulatória: a entoação e o gesto são ativos e objetivos por tendência. Ao entoar ou gesticular, uma pessoa assume a posição social ativa, com respeito a certos valores específicos, sendo esta posição condicionada pelas próprias bases de sua existência social (VOLOCHINOV; BAKHTIN, 1926). Esta posição social ativa se constitui quando o sujeito fala, pois, ao falar, ele responde a algo já dito antes e se coloca em relação aos enunciados anteriores, criando o elo da comunicação proposto pelo Círculo de Bakhtin.

Por outro lado, a entoação é uma característica dada pelo produtor também na escrita, podendo ser identificada por meios específicos, como marcas textuais, pontuação e marcas notacionais, sendo relacionada ao extraverbal e ao julgamento de valor presumido. Portanto, "[...] a emoção, o juízo de valor, a expressão são estranhos à palavra da língua e surgem unicamente no processo do seu emprego vivo em um enunciado concreto." (BAKHTIN, 2003, p.292). Dessa forma, é possível afirmar que a entoação transforma um termo em um enunciado acabado e as formas de sua compreensão são variáveis e polifônicos, como veremos a seguir.

\section{Os conceitos axiológicos em análise}

Para discutir teórico-analiticamente os conceitos axiológicos apresentados, escolheu-se uma peça publicitária da empresa Nestlé, produzida por Bernardo Leite, em 15 de julho de 2006, para a mídia impressa. Esta propaganda, disponibilizada no sítio Desencannes, o qual apresenta "pérolas da propaganda não publicadas" - material produzido para circulação social, porém não aceito para a divulgação do produto por diversas razões, mas que não deixa de ser um material para estudar o uso da linguagem em nossa sociedade, já que esse enunciado também se faz presente na vida das pessoas, uma vez que está disponível na rede 
mundial. Na apresentação do sítio, o responsável afirma: "Aqui, ninguém julga se a peça funcionaria. O que vale é o humor inteligente, a sacadinha, a propaganda impublicável. Pode-se criar, comentar, discordar, defender. Mas o que importa é a ideia pela ideia." (DESENCANNES, 2012). Assim, o que tem mais valor, neste caso, é a publicidade como forma de humor, através da imagem e da escrita.

Atualmente, a comunicação por meio de imagens tem sido um recurso muito utilizado, o que leva o indivíduo a ter que praticar o olhar para entender o mundo atual (NOGUEIRA, 2007). As imagens estão presentes em quase todos os textos que utilizamos, por isso "[...] é impossível compreender os textos, até mesmo as suas partes linguísticas somente, sem ter uma idéia clara de como esses outros elementos podem estar contribuindo para o significado do texto." (KRESS, 2000 apud NOGUEIRA, 2007, p.53). Esses outros elementos fazem parte do que seria o extraverbal, já discutido por Volochinov e Bakhtin (1926), Bakhtin (2003) e Sobral (2009).

Além disso, a presença de recursos imagéticos nos textos introduz o conceito de multimodalidade nos estudos sobre leitura, que não são aqui discutidos por não serem o foco teórico do trabalho. Os gêneros orais e escritos são considerados multimodais na medida em que, "[...] quando falamos ou escrevemos um texto, estamos usando no mínimo dois modos de representação: palavras e gestos, palavras e entonações, palavras e imagens, palavras e tipografias, palavras e sorrisos, palavras e animações etc." (DIONÍSIO, 2005 apud NOGUEIRA, 2007, p.54). Dessa forma, o texto em análise se enquadra na classificação de multimodal, não podendo ser compreendido sem considerar o dito por meio do texto, da imagem e o contexto compreendido pelos envolvidos na interação.

A propaganda apresenta uma moldura formada por corações embrulhados em papel chumbo vermelho, dispostos em formas próprias para colocar docinhos de festa, arrumados formando uma moldura completa entorno do texto, como disposto numa mesa de festa, típico de conhecimentos pressupostos aos consumidores de produtos da Nestlé, isto é, já presumidos pelo produtor (VOLOCHINOV; BAKHTIN, 1926; FARACO, 2009). O uso das cores em um texto consiste em chamar a atenção, guiar o olho do leitor e estabelecer relações lógicas e possíveis aos seus sentidos. Elas influenciam psicologicamente os seres humanos e são mais ligadas à emoção do que própria e simplesmente à forma. A escolha da cor na propaganda é muito importante, uma vez que exerce uma ação tríplice sobre o indivíduo que recebe a comunicação visual: impressionar, expressar e construir sentidos. Nesse aspecto, "[...] a cor é vista e impressiona a retina. É sentida: provoca uma emoção. E é construtiva, pois, tendo um significado próprio, tem valor de símbolo e capacidade, portanto de construir uma linguagem própria que comunique uma ideia." (FARINA; PEREZ; BASTOS, 2006, p.13). 
Muitas teorias científicas têm procurado explicar de maneira definitiva a visão da cor, mas o certo é que determinadas cores dão a sensação de proximidade e outras de distância. De acordo com os estudos realizados pelo psicólogo suíço Max Lüsher, experiências têm provado ser o vermelho puro excitante, ao olhar para esta cor, há uma elevação da pressão arterial e o ritmo cardíaco do indivíduo é alterado (FARINA; PEREZ; BASTOS, 2006).

Observando a peça publicitária, percebe-se uma materialidade constituída por recursos linguísticos e visuais, com um propósito comunicativo que é estimular nos interlocutores o desejo de adquirir o produto, de saboreá-lo, numa determinada situação interativa de comunicação: a relação de divulgação do produto (VOLOCHINOV; BAKHTIN, 1926; BAKHTIN, 2003). No caso, a cor vermelha chama a atenção do leitor ao impulsionar a atenção e a adesão aos elementos em destaque. Segundo os estudos de Lüsher (apud FREITAS, 2007), o vermelho significa desejo, todas as formas de ânsia e apetite insaciável, é uma cor ativa. Relacionada com o formato de corações apresentados na moldura da publicidade, este efeito é reforçado. Tanto a cor quanto o formato selecionados para a propaganda estão relacionadas ao contexto de produção de leitura da publicidade, consequentemente, aos modos de produção do extraverbal e dos valores imputados (VOLOCHINOV; BAKHTIN, 1926; BAKHTIN, 2003; CLARK; HOLQUIST, 1998; FARACO, 2009; GERALDI, 1997; SOBRAL, 2009).

Figura 1 - Peça publicitária da Nestlé

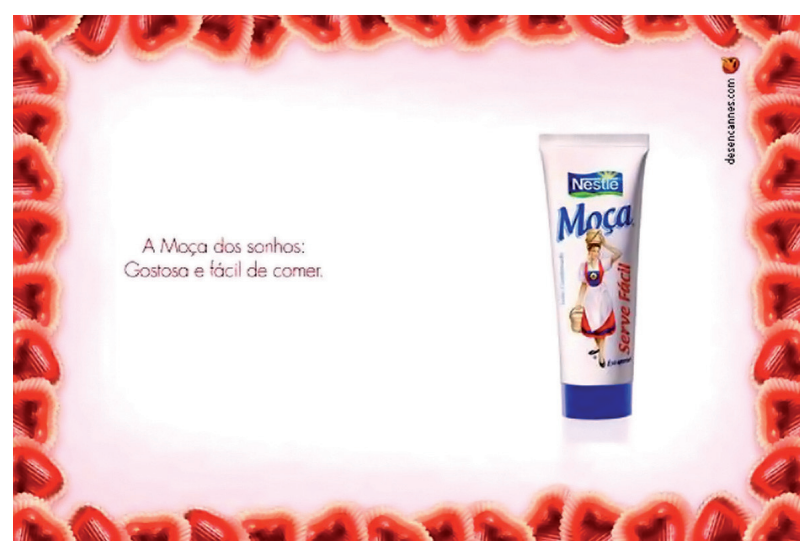

Fonte: Desencannes (2012).

Agregada à escolha da cor e da forma, ao lado direito encontra-se a foto do produto anunciado: Leite Condensado Nestlé Moça serve fácil. Uma embalagem prática, no formato de bisnaga, a qual, para abrir, não necessita de abridor, como 
na versão em lata, apenas desrosquear a tampa. Isto justifica a ideia do serve fácil, é só abrir e usar, inclusive seu formato favorece a ideia de que, com o próprio tubo, é possível fazer as decorações que estão nas bordas. Esse sentido de serve fácil, por ser bisnaga e não precisar de abridor, é justamente o tom valorativo do enunciado, já proposto pelo Círculo de Bakhtin (VOLOCHINOV; BAKHTIN, 1926), discutido por Sobral (2009) e por nós na seção anterior. Justamente pelos leitores saberem que esse tipo de embalagem é mais fácil de manusear, o nome dado ao produto pressupõe esse conceito social no interlocutor, neste caso, o extraverbal, nos seus três elementos: a) o horizonte espacial ideacional, b) o conhecimento e a compreensão comum da situação comunicativa, c) a avaliação comum da situação, pressupostos essenciais para que a propaganda seja lida, compreendida e aceita como um enunciado, no ato comunicativo.

Ainda na sua descrição, o tubo tem como ilustração uma jovem camponesa suíça, carregando um balde de leite, logomarca da empresa Nestlé no mundo todo. A condensação do leite, quando surgiu o produto, tinha como objetivo conserválo para possibilitar o seu transporte e armazenamento e, ao chegar ao destino, era diluído em água, sendo utilizado em forma líquida (LEITE..., 2012). No Brasil, o produto passou a ser conhecido como "a Moça" e o leite condensado como "Leite Moça", configurando, assim, os conhecimentos historicamente construídos, conforme ensina Geraldi (1997).

No campo da comunicação, a cor tem uma função bem definida e específica de ajudar na clareza da mensagem a ser transmitida. Analisando os elementos constitutivos do sistema visual que compõem a embalagem do produto, tem-se o fundo em branco sobre o qual aparece a imagem da camponesa, carregando um balde de leite, as palavras "Nestlé" e "Moça" em azul e "serve fácil" em vermelho, portanto, as cores básicas da peça publicitária são o vermelho, o azul e o branco, as duas primeiras são cores primárias e a última, neutra, própria a fundos, para destacar os aspectos linguísticos e não verbais. Essa exposição de cores primárias é justamente uma marca da entoação discutida pelo Círculo de Bakhtin, já que ela carrega elementos extraverbais que são complementares ao enunciado, que valoram o produto ao interlocutor. A singeleza do branco ao fundo justamente reflete a pureza do produto (leite tem cor branca), que é representado por uma "moça", vestida delicadamente como camponesa, nas mesmas cores que há em toda a embalagem. Nesse sentido, há, aí, a entoação avaliativa (VOLOCHINOV; BAKHTIN, 1926), bem discutida por Sobral (2009), ao comentar que ela se constitui em relação à resposta ativa presumida do interlocutor, justamente por seu produtor saber os valores comuns a ambos. Esses valores são as cores, seus significados aos leitores brasileiros, a moça, sua forma típica camponesa, trajes e cores, e o produto, também muito conhecido por todos. Com isso, a entoação avaliativa presumida se configura como adequada à propaganda impressa aqui analisada. 
A principal função da cor na embalagem é chamar a atenção do público consumidor (FARINA; PEREZ; BASTOS, 2006) e liberar a imaginação e a criatividade do homem. A cor vermelha chama a atenção com mais rapidez e intensidade do que as demais, por isso, além de ser utilizada na roupa da personagem, também é utilizada na expressão "serve fácil", bem como em toda moldura do enunciado. Outros aspectos importantes relacionados a essa cor são: impõe vivacidade e energia, aspectos que atribuem uma carga simbólica no sentido de transmitir afeto, amor e a sensação de acolhimento e, ainda, sob o ponto de vista simbólico, mas derivado de uma relação de semelhança, está associada ao pecado, à volúpia e à sensualidade, atribuindo à personagem e, consequentemente, ao produto em si, uma carga atraente e tentadora (ALMEIDA et al., 2009), numa possível leitura inferencial que o enunciado permite. Por sua vez, o azul normalmente está relacionado aos aspectos de segurança e confiabilidade, imbuídos tanto para a marca quanto para o produto. Já a cor branca remete à pureza, ao frescor, à limpeza e ao universo lácteo. Essas constituições de cores são marcas axiológiocas possíveis de observação no enunciado (VOLOCHINOV; BAKHTIN, 1926; BAKHTIN, 2003; SOBRAL, 2009). O branco presente no balde remete à sensação indicial de leite fresco, que acabou de vir da ordenha, em virtude da posição corporal da moça camponesa com os baldes na cabeça e na mão direita, o que ativa na mente do consumidor a qualidade do produto, o conceito de valor presumido (VOLOCHINOV; BAKHTIN, 1926; BAKHTIN, 2003; SOBRAL, 2009).

Por sua vez, ao se observar os recursos linguísticos, temos "A MOÇA DOS SONHOS: GOSTOSA E FÁCIL DE COMER", que é a parte percebida ou realizada linguisticamente do enunciado. Analisada como frase isolada, fora de um contexto delimitado, sem direcionalidade, está sujeita a várias interpretações, podendo gerar ambiguidades, até mesmo sem noções de sentidos possíveis. Já ao constituir-se em um enunciado concreto, no gênero discursivo propaganda impressa, marcado pela presença de um enunciador que considera os possíveis interlocutores com uma finalidade específica, que é a divulgação da nova embalagem de um produto conhecido pela população, e com valores já presumidos e definidos (VOLOCHINOV; BAKHTIN, 1926; BAKHTIN, 2003), tem sua significação delimitada por meio do contexto e dos julgamentos de valores presumidos pela publicidade, pelo produto e pelas marcas linguísticas e visuais ali definidas. O que antes estava aberto às diversas possibilidades de interpretação, nesse contexto, encontra-se delimitado pelos valores do grupo social que constitui as possibilidades de compreensão do extraverbal do enunciado (VOLOCHINOV; BAKHTIN, 1926; BAKHTIN, 2003; GERALDI, 1997; FARACO, 2003; SOBRAL, 2009). Assim, "A MOÇA DOS SONHOS: GOSTOSA E FÁCIL DE COMER" não pode ser qualquer uma, graças ao contexto do enunciado e as circunstâncias não linguísticas conhecidas pelos interactantes. Dessa forma, 
necessariamente deve ser entendido como "Moça, leite condensado da Nestlé", marca reconhecida entre os brasileiros.

O enunciado só tem a significação dada pelo produtor se for considerado o entorno físico, ideológico e cultural do discurso verbal. No entorno cultural, por exemplo, "moça dos sonhos" significa uma moça especial; por sua vez, "gostosa" pode ser um conceito puramente estético relacionado à mulher bonita, atraente, com o corpo bonito e sensual, não relacionado ao paladar, fugindo ao proposto pela propaganda, ou referir-se ao produto que é conhecido como "moça" e tem um sabor marcante e conhecido. Por outro lado, a entoação de "gostosa" pelo leitor já define por si só um conceito de algo com bom paladar, que é realmente o que o produto anunciado tem. Ao mesmo tempo, "fácil de comer", apesar da ambiguidade existente, que pode levar a conotações sexuais, inclusive, também demonstra uma entoação valorativa do produto, já que o leite condensado na bisnaga é muito mais fácil de ser comido do que em outro recipiente, como na tradicional lata que precisa de um abridor, por exemplo. São os valores que envolvem os participantes do discurso que dão significado ao enunciado (VOLOCHINOV; BAKHTIN, 1926; BAKHTIN, 2003; GERALDI, 1997; SOBRAL, 2009), proporcionando até mesmo o humor, que, neste caso, é constituído pela ambiguidade identificada nos recursos linguísticos, oferecendo, assim, novos discursos possíveis. Dessa forma, ao se considerar os recursos extraverbais como a escolha da cor, os corações em formas de doces que constituem a moldura, juntamente com as marcas linguísticas, é possível ter outros sentidos ao enunciado, pois não se trata de qualquer moça (menina jovem), mas, sim, da moça ilustrada na embalagem. Essa polissemia remete à pretensa conotação de que não se trata de qualquer mulher jovem, considerada na gíria brasileira atual como "gostosa" - daí o emprego no texto da polissemia a este vocábulo, no sentido de bonita e com corpo perfeito, e fácil de se relacionar sexualmente com um homem; como também, à leitura do produto chamado "Leite Moça", que é "gostoso no seu paladar" " "fácil de ser consumido", pela comodidade da nova embalagem.

Com essa análise, pretendeu-se demonstrar que, no estudo dos enunciados concretos, os conceitos de julgamento de valor, entoação e extraverbal, não são desconsiderados, pois os enunciados são moldados pela antecipação de uma resposta, o que não é possível acontecer se os valores do grupo social em questão forem desconhecidos e, até mesmo, desconsiderados (VOLOCHINOV; BAKHTIN, 1926; BAKHTIN, 2003; SOBRAL, 2009).

\section{Considerações finais}

O enunciado se constitui por sua direcionalidade certa, ou seja, parte de um locutor para um interlocutor, em contextos sócio-histórico-ideológicos específicos (VOLOCHINOV; BAKHTIN, 1926; BAKHTIN, 2003). Está diretamente 
ligado ao contexto extraverbal, não podendo ser compreendido se deslocado do contexto imediato que deve ser conhecido dos que estão envolvidos no processo comunicativo. Por isso, afirma-se que ele nasce e finda no processo de interação social entre os participantes da enunciação. Ele é constituído por aspectos verbais e também não verbais que se organizam de acordo com as especificidades das esferas de comunicação social e, como defendido neste texto, pela situação extraverbal ligada a eles.

Dessa forma, este texto objetivou compreender como os conceitos axiológicos se configuram no gênero discursivo propaganda impressa. Para isso, foram discutidos os conceitos de extraverbal, julgamento de valor e entoação pelo Círculo de Bakhtin e por outros pesquisadores, procurando compreender como eles se constituem num gênero discursivo de circulação social definida, como manifestação do complexo mundo da linguagem humana. Como resultado, notase que os conceitos axiológicos propostos pelo Círculo de Bakhtin auxiliam a compor uma leitura mais adequada de enunciados escritos, como o exemplificado, configurando-se com material linguístico e não verbal, constituindo possibilidades de compreensão mais amplas do processo enunciativo que se forma no momento de leitura desse gênero discursivo específico.

MENEGASSI, R. J.; CAVALCANTI, R. S. Axiological Bakhtinian concepts in print advertisement. Alfa, São Paulo, v.57, n.2, p.433-449, 2013.

- ABSTRACT: This article addresses the axiological aspects in the extra-verbal, judgment value and intonation concepts, discussed within the ideology of the Bakhtin Circle, presented specifically by Volochinov and Bakhtin (1926), Bakhtin andVolochinov (2006) and Bakhtin (2003). This paper also relates the Bakhtinian concepts with studies carried out by researchers such as Geraldi (1997), Clark and Holquist (1998), Souza (2002), Tezza (2003), Morson and Emerson (2008), Faraco (2009) and Sobral (2009), and discusses the way in which they are presented in real advertisements within social communication situations. The above-mentioned concepts are also exemplified in one advertisement produced by the press. The different meanings in the reading are revealed when the concepts discussed are taken into consideration.

- KEYWORDS: Extra-verbal. Value judgment. Intonation. Enunciation.

\section{REFERÊNCIAS}

ALMEIDA, C. de S. et al. Personagem de marca: análise semiótica da moça leiteira. In: CONGRESSO BRASILEIRO DE CIÊNCIAS DA COMUNICAÇÃO, 32., 2009, Curitiba. Anais... Curitiba: Intercom, 2009. Disponível em: <http://www.intercom. org.br/papers/nacionais/2009/resumos/R4-0921-1.pdf >. Acesso em: 05 abr. 2012.

BAKHTIN, M. Estética da criação verbal. 4.ed. São Paulo: Martins Fontes, 2003. 
BAKHTIN, M.; VOLOCHINOV, V. N. Marxismo e filosofia da linguagem. 6.ed. São Paulo: Hucitec, 2006.

CÂMARA JUNIOR, J. M. Dicionário de linguística e gramática: referente à língua portuguesa. Petrópolis: Vozes, 2007.

CLARK, K.; HOLQUIST, M. Mikhail Bakhtin. Tradução de J. Guinsburg. São Paulo: Perspectiva, 1998.

DESSENCANNES. Disponível em: <http://www.desencannes.com/perolas/ detalhes_impressa.php?id=115\&c=t>. Acesso em: 05 abr. 2012.

FARACO, C. A. Linguagem \& Diálogo: as ideias linguísticas do círculo de Bakhtin. São Paulo: Parábola, 2009.

FARINA, M.; PEREZ, C.; BASTOS, D. PSicodinâmica das cores em comunicação. São Paulo: Edgard Blucher, 2006.

FERREIRA,A. B. de H. Miniaurélio: o minidicionário da língua portuguesa. Curitiba: Positivo, 2008.

FREITAS,A. K. M. de. Psicodinâmica das cores em comunicação. Nucom, Limeira, v.4, n.12, p.1-18, out./dez. 2007. Disponível em <http://www.iar.unicamp.br/lab/ luz/ld/Cor/psicodinamica_das_cores_em_comunicacao.pdf $>$. Acesso em: 05 abr. 2012

GERALDI, J. W. Portos de passagem. 4.ed. São Paulo: Martins Fontes, 1997. . O texto na sala de aula. 2.ed. Cascavel: Assoeste, 1984.

LEITE Condensado. Historia do leite condensado. Disponível em: <http://www. leitecondensado.com/?p=4>. Acesso em: 05 abr. 2012.

MORSON, G. S.; EMERSON C. Mikhail Bakhtin: criação de uma prosaística. Tradução de Antonio de Pádua Danesi. São Paulo: EDUSP, 2008.

NOGUEIRA, M. C. B. Ouvindo a voz do (pré)adolescente brasileiro da geração digital sobre o livro didático de inglês desenvolvido no Brasil. 2007. 182f. Dissertação (Mestrado em Letras) - Pontifícia Universidade Católica do Rio de Janeiro, Rio de Janeiro, 2007. Disponível em: <http://www.maxwell.lambda.ele. pucrio.br/Busca_etds.php?.strSecao=resultado\&nrSeq=10439@1>. Acesso em: 23 nov. 2011.

SOBRAL, A. Do dialogismo ao gênero: as bases do pensamento do Círculo de Bakhtin. Campinas: Mercado de Letras, 2009.

SOUZA, G. T. Introdução à teoria do enunciado concreto do círculo de Bakhtin/ Volochinov/Medvedev. São Paulo: Humanistas: FFLCH, 2002. 
TEZZA, C. Entre a prosa e a poesia: Bakhtin e o formalismo russo. Rio de Janeiro: Rocco, 2003.

VOLOCHINOV, V. N.; BAKHTIN, M. Discurso na vida e discurso na arte: (sobre poética sociológica). Tradução de Carlos Alberto Faraco e Cristóvão Tezza [para fins didáticos]. 1926. Versão da língua inglesa de I. R. Titunik a partir do original russo.

Recebido em agosto de 2012

Aprovado em novembro de 2012 